\title{
Comparison of Anterior Cervical Discectomy Fusion Techniques: Bladed and Non Bladed PEEK Cages
}

\author{
Mustafa GUVEN ${ }^{1}$, Murat COSAR ${ }^{1}$, Bahadir ALKAN ${ }^{1}$, Adem Bozkurt ARAS ${ }^{1}$, Tarik AKMAN ${ }^{1}$, Ozbey SAFAK ${ }^{1}$, \\ Oznur KARAARSLAN ${ }^{1}$, Davut CEYLAN², Mehmet TOKMAK ${ }^{3}$
}

${ }^{1}$ Çanakkale 18 Mart University, School of Medicine, Department of Neurosurgery, Çanakkale, Turkey

${ }^{2}$ Sakarya University, School of Medicine, Department of Neurosurgery, Sakarya, Turkey

${ }^{3}$ Medipol University, School of Medicine, Department of Neurosurgery, Istanbul, Turkey

\section{ABSTRACT}

AIM: The aim of this study is to compare the different types of fusion materials known as PEEK cages used during anterior cervical discectomy (ACD) surgery.

MATERIAL and METHODS: A total of 67 patients were operated and evaluated retrospectively under two groups (group A: 35 PEEK cage patients, group B: 32 bladed PEEK cage patients) between 2009 and 2013. Preoperative and postoperative (postoperative first day, postoperative 1st, 3rd and 12-24th mo) images were obtained. The cervical disc heights, cervical and segmental lordotic angles of the operated levels were calculated. Pain assessment was performed and fusion rates were also compared. Mann-Whitney $U$ test was applied to compare the outcomes.

RESULTS: The pain scores (especially for arm pain) were decreased significantly in both groups after surgery regardless of the type of operation technique $(\mathrm{P}<0.05)$. There were no significant differences between both groups at the disc height measurements of operated levels in postoperative periods $(P>0.05)$. In addition to these; there was no significant difference between both groups of segmental and cervical lordodic angles in postoperative periods $(P>0.05)$. There was no statistically significant difference between the fusion rates and pain scores of both groups $(P>0.05)$.

CONCLUSION: The PEEK cage and bladed PEEK cages can be used safely to obtain fusion after ACD.

KEYWORDS: Anterior cervical discectomy, Cage, Fusion, PEEK Cage

\section{INTRODUCTION}

Anterior cervical discectomy (ACD) is an operation technique that has been routinely used for a few decades to treat the cervical disc diseases, which may cause neurological deficits, radiculopathy, etc. During this time period, a few operative techniques have been developed and added to the ACD to increase the efficacy and success of the technique. Most of these techniques such as autolog grafts, allografts, hydroxyapatite (HA) ceramic grafts, titanium, poly etheretherketone, carbone cages and plates are focused on fusion and maintain the alignment of the cervical vertebrae
$(2,3,7,13)$. Polyetheretherketone (PEEK) cage and autograft and/or calcium phosphate (CP) and HA combinations were also studied to increase the fusion rate $(7,11)$. Collapse of the operated levels, pseudoarthrosis, and dislodgement of the fusion materials are the major problems with ACD and fusion. However, the choice of the materials for interbody fusion is still controversial $(2,7)$.

During this developmental process, some of these biomedical tools and especially PEEKones were marketed more widely than its relatives. The usage of PEEK cages increased, especially in the last decade of this century, and some modulations of 
these PEEK cages were developed and added to the surgical spectrum such as bladed ones. The bladed PEEK cages were suggested to provide stability to the vertebrae or claimed to decrease the blood supply of the vertebrae corpus. So, there is dilemma on the effectiveness of the bladed PEEK cages as against the simple ones $(7,11,12,17)$.

We conducted a retrospective study to assess and compare the postoperative changes that occurred after $A C D$ and fusion techniques such as PEEK cages and bladed PEEK cages between 2009 and 2013 at Canakkale 18 Mart University, Faculty of Medicine, Department of Neurosurgery. The aim of this study was to report and compare clinical and radiologic findings at the height of the operated level, fusion rates and angles of cervical and segmental area.

\section{MATERIAL and METHODS}

Thirty-five patients were investigated in Group A and 32 patients were investigated in Group B. The inclusion criteria were as follows: Magnetic resonance imaging findings correlated with clinical picture; single level affected; symptoms of radiculopathy, first cervical surgery, and either urgent need for surgical intervention or no response to at least 6 weeks of conservative treatment. In addition, exclusion criteria were a prior percutaneous procedure to address cervical and/or radicular pain (nucleotomy, chemonucleolysis, epidural steroid injection, or others), multilevel disc herniation, significant degenerative spinal disorder, fracture, infection, tumors and deformity of vertebrae, chronic systemic illness and cervical kyphotic postured patients. No exclusion was made based on sex, age or the intensity of preoperative clinical findings. All patients had plain AP and lateral radiographs, CT scans and MRI scans of their cervical spine, before surgery. Similar sized cages were used in both groups $(5 \mathrm{~mm}$ thickness, 16 $\mathrm{mm}$ transverse and $14 \mathrm{~mm}$ antero-posterior diameters).

Group A consisted of 35 patients (16 men and 19 women; median age 45.2 years) who underwent $A C D$ with PEEK cage fusion (Titania ${ }^{\circledR}$, Izmir-Turkey). Group B was comprised of 32 patients ( 15 men and 17 women; median age 43.4 years) who underwent ACD with bladed PEEK cage fusion (Medikon®, Ankara-Turkey).

All operations in both groups were performed under general anesthesia. Fluoroscopy was used to detect the operation level of the vertebrae. ACD and osteophytectomy were performed microsurgically after the distraction of affected level. In both groups, the posterior longitudinal ligament was opened and a portion of the ligament was removed to decompress the spinal cord and affected nerve roots. In each of cases, the endplates of the upper and lower vertebrae were decorticated slightly while caring the surrounding cartilage endplate. The PEEK cages and bladed PEEK cages were prepared via injecting bone grafts (Osteotech $₫$, Eatontown, NJ-USA). The PEEK cages in group $A$ and bladed PEEK cages in group $B$ were placed while the vertebrae were still distracted. The affected vertebrae were re-distracted after the controlling of graft position with fluoroscopy. All patients in both groups were suggested to wear a soft cervical collar for the first 3 weeks after surgery.
The patients were evaluated routinely with visual analogue score (VAS) in each day at the preoperative and early postoperative period. This clinical evaluation also continued at the postoperative control period. Odom's criteria were used at the last follow-up for the clinical evaluation as excellent, good, fair and poor.

Radiological findings at the height of the operated level, cervical and segmental lordotic angles and fusion rates for both groups were evaluated in 5 time points: preoperatively and postoperative $1^{\text {st }}$ day, $1^{\text {st }}$ month, $3^{\text {rd }}$ month and $1^{\text {st }}$ year [12 to 24 mo's (mean 18 mo's)]. Disc height was measured using the images in the mid-sagittal plane via the help of software programme of computed tomography (Toshiba $₫$, Prospeed Helical CT). Segmental and cervical lordotic angles of both groups were also measured with lateral standing $\mathrm{x}$-ray graphy preoperatively and postoperatively.

Lordosis of the cervical spine (C2-T1) was measured via the angle between the lines drawn from the upper endplate of $\mathrm{C} 2$ and the lower endplate of $\mathrm{C} 7$ vertebrae. Furthermore, segmental lordosis at the operated level was measured via the angle between the lines drawn from the upper endplate of the upper vertebra and lower endplate of the lower vertebra (Figures 1A, B) (8).

Fusion of the operated levels in both groups were evaluated via radiographs and CT scans at the $3^{\text {rd }}$ and $12-24^{\text {th }}$ mo's follow-up as poor, average, good or excellent by a radiologist who is unrelated with the study. The presence of continuous trabecular bone bridges in at least one of the locations such as anterior, within and posterior of the cage was evaluated for fusion (14).

This Mann-Whitney $U$ test was used to compare changes in disc heights, segmental and cervical lordotic angles and fusion rates of both groups [preoperatively to postoperative first day, $1^{\text {st }}$ month, $3^{\text {rd }}$ month and $1^{\text {st }}$ and/or $2^{\text {nd }}$ year postoperative time point (12 to $24^{\text {th }}$ months).

The same test was used for to compare VAS scores and Odom's criteria for each group. $p$ values $<0.05$ were considered significant.

\section{RESULTS}

The patients' demographic data are shown in Table I. The list of VAS scores of arm pain for both groups is seen in Table II. The mean arm pain VAS scores for PEEK cage group preoperatively and 12-24 months periods were $8.1 \pm 0.7$ and $2.2 \pm 0.2$, respectively. The VAS scores of arm pain for bladed PEEK cage group were $8.4 \pm 0.6$ and $2.0 \pm 0.3$, respectively. These decrease levels were significant $(p<0.05)$ for both groups. Intergroup comparisons of VAS scores revealed no significant differences preoperatively and postoperatively (Table II).

Odom's criteria were performed to evaluate the clinical relief of symptoms at the last follow-up in both groups. The Odom's criteria were numbered as excellent: 4 , good: 3 , fair: 2 , poor: 1. Satisfactory results were obtained in both groups and the intergroup comparisons of Odom's criteria did not revealed 
significant differences. However, intragroup comparison of preoperative and postoperative evaluations showed significant differences $(p<0.05)$ (Table II).

The mean values for operated-level disc heights in group $A$ at the 5 time points are shown in Table III. Statistical analysis revealed significant change in mean disc height from preoperative time point to day $1(3.75 \pm 0.32 \mathrm{~mm}$ vs. $5.52 \pm 1.15$ $\mathrm{mm}$, respectively; $\mathrm{p}<0.05)$. Also, statistical analysis revealed significant change in mean disc height from preoperative time point to $1^{\text {st }}$ and $3^{\text {rd }}$ months $(3.75 \pm 0.32 \mathrm{~mm}$ vs. $5.20 \pm 0.90$ $\mathrm{mm}$ and $5.05 \pm 1.05 \mathrm{~mm}$, respectively; $\mathrm{p}<0.05$ and $\mathrm{p}<0.05$ ). In addition to these, there was a significant increase in disc height from preoperative time point to the $12-24^{\text {th }}$ months postoperative time point (mean $18 \mathrm{mo}$ 's) (3.75 $\pm 0.32 \mathrm{~mm}$ vs. $4.80 \pm 0.95 \mathrm{~mm} \mathrm{p}<0.05$ ) (Table III).

The mean values for operated-level disc heights in group $B$ at the 5 time points are shown in Table III. Statistical analysis revealed significant change in mean disc height from preoperative time point to day $1(3.85 \pm 1.0 \mathrm{~mm}$ vs. $5.50 \pm 1.15$ $\mathrm{mm}$, respectively; $\mathrm{p}<0.05)$. Also, statistical analysis revealed significant change in mean disc height from preoperative time point to $1^{\text {st }}$ and $3^{\text {rd }}$ months $(3.85 \pm 1.0 \mathrm{~mm}$ vs. $5.15 \pm 0.90$ $\mathrm{mm}$ and $5.0 \pm 0.85 \mathrm{~mm}$, respectively; $\mathrm{p}<0.05$ and $\mathrm{p}<0.05)$. In addition to these, there was a significant increase in disc height from preoperative time point to the $12-24^{\text {th }}$ months postoperative time point (mean 18 months) $(3.85 \pm 1.0 \mathrm{~mm}$ vs. $4.81 \pm 0.78 \mathrm{~mm} ; \mathrm{p}<0.05$ ) (Table III).

The mean values for operated-level segmental lordotic angles in group $A$ at the 5 time points are shown in Table IV. Statistical analysis revealed significant change in mean segmental lordotic angles from preoperative time point to day 1 (0.18 \pm 0.06 vs. $4.2 \pm 0.48$, respectively; $p<0.05$ ). Also, statistical analysis revealed a significant change in mean segmental
Table I: Demographic Distribution and Operation Levels of the Both Groups

\begin{tabular}{lccc}
\hline & $\begin{array}{c}\text { Group A } \\
\text { (n:35) }\end{array}$ & $\begin{array}{c}\text { Group B } \\
\text { (n:32) }\end{array}$ & p \\
\hline Age (year) & 45.2 & 43.4 & NS \\
\hline Follow up time (mo) & 22 & 24 & NS \\
\hline F/M ratio & $19 / 16$ & $17 / 15$ & NS \\
\hline Operation Level (n) & & & NS \\
\hline C4-5 & 5 & 5 & \\
\hline C5-6 & 16 & 14 & \\
\hline C6-7 & 14 & 13 & \\
\hline
\end{tabular}

Table II: The VAS Scores and Odoms Criteria of Both Groups

\begin{tabular}{lccc}
\hline & Group A & Group B & p \\
\hline Preop VAS & $8.1 \pm 0.7$ & $8.4 \pm 0.6$ & \\
\hline Postop VAS & $2.2 \pm 0.2$ & $2.0 \pm 0.3$ & \\
\hline$p$ & $<0.05$ & $<0.05$ & \\
\hline Odom's Criteria & & & NS \\
\hline Excellent & 12 & 11 & \\
\hline Good & 22 & 20 & \\
\hline Fair & 1 & 1 & \\
\hline Poor & 0 & 0 & \\
\hline$p$ & $<0.05$ & $<0.05$ & \\
\hline
\end{tabular}

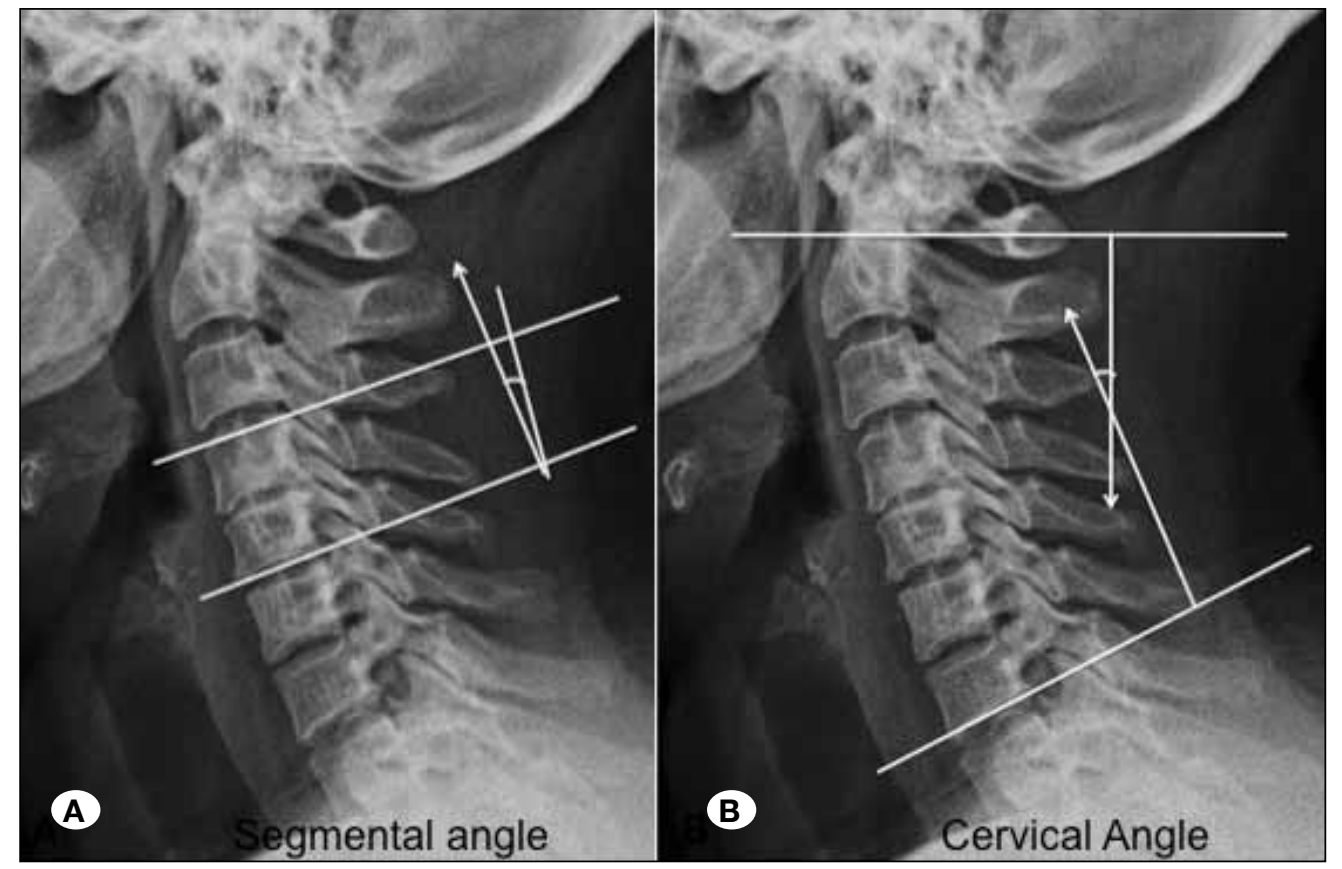

Figure 1A, B: The figures showing the segmental and cervical angle measurements. 
lordotic angles from the preoperative time point to $1^{\text {st }}$ and $3^{\text {rd }}$ months $(0.18 \pm 0.06$ vs. $2.20 \pm 0.30$ and $1.90 \pm 0.25$, respectively; $p<0.05$ and $p<0.05)$. In addition to these, there was a significant increase in segmental lordotic angles from preoperative time point to the $12-24^{\text {th }}$ mo's postoperative time point (mean 18 months) $(0.18 \pm 0.08$ vs $1.15 \pm 0.20 ; \mathrm{P}<0.05)$ (Table IV).

The mean values for operated-level segmental lordotic angles in group B at the 5 time points are shown in Table IV. Statistical analysis revealed significant change in mean segmental lordotic angles from preoperative time point to day $1(0.32 \pm 0.08$ vs. $4.90 \pm 1.0$, respectively; $\mathrm{p}<0.05)$. Also, statistical analysis revealed significant change in mean segmental lordotic angles from preoperative time point to $1^{\text {st }}$ and $3^{\text {rd }}$ months $(0.32 \pm 0.08$ vs. $3.10 \pm 0.60$ and $2.31 \pm 0.51$, respectively; $p<0.05$ and $p<0.05$ ). In addition to these, there was a significant increase in segmental lordotic angles from preoperative time point to the $12-24^{\text {th }}$ months postoperative time point (mean 18 months) ( $0.32 \pm 0.08$ vs $1.5 \pm 0.33 \mathrm{~mm}$; $\mathrm{p}<0.05$ ) (Table IV).

The mean values for cervical lordotic angles in group $A$ at the 5 time points are shown in Table V. Statistical analysis did not revealed significant change in mean cervical lordotic angles from preoperative time point to day $1(12.10 \pm 1.80$ vs. 10.60 \pm 1.58 , respectively; $\mathrm{p}<0.05$ ). However, statistical analysis revealed significant change in mean cervical lordotic angles from preoperative time point to $1^{\text {st }}$ and $3^{\text {rd }}$ months $(12.10 \pm 1.80$ vs. $15.60 \pm 2.22$ and $14.10 \pm 2.06$, respectively; $p<0.05$ and $\mathrm{p}<0.05)$. In addition to these, there was a significant increase in cervical lordotic angles from preoperative time point to 12 $24^{\text {th }}$ months postoperative time point (mean 18 months) (12.10 \pm 1.80 vs. $14.04 \pm 1.60 ; p<0.05$ ) (Table V).

The mean values for cervical lordotic angles in group $B$ at the 5 time points are shown in Table V. Statistical analysis did not revealed significant change in mean cervical lordotic angles from preoperative time point to day $1(10.65 \pm 1.46$ vs. 9.40 \pm 1.24 , respectively; $p<0.05$ ). However, statistical analysis revealed significant change in mean cervical lordotic angles from preoperative time point to $1^{\text {st }}$ and $3^{\text {rd }}$ months $(10.65 \pm 1.46$ vs. $14.32 \pm 2.01$ and $14.01 \pm 1.58$, respectively; $p<0.05$ and $\mathrm{P}<0.05)$. In addition to these, there was a significant increase in cervical lordotic angles from preoperative time point to the $12-24^{\text {th }}$ months postoperative time point (mean 18 months) (10.65 \pm 1.46 vs. $13.52 \pm 1.75 ; p<0.05$ ) (Table V).

The comparison of fusion rates at the operated levels of all patients in the $3^{\text {rd }}$ and $12^{\text {th }}-24^{\text {th }}$ months after surgery showed no significance between the groups. The $3^{\text {rd }}$ months follow-up PEEK cage (Group A) and bladed PEEK cage groups (Group B) were showed $55 \%$ and $60 \%$ fusion rates, respectively. In addition to these, all patients of both groups had $100 \%$ good and excellent fusion rates at the operated levels in the $12^{\text {th }}$ $24^{\text {th }}$ months after surgery (Figures $2 A-F, 3 A-F$ ).

There were no significant differences between the groups' mean preoperative data for pain VAS scores, Odom's criteria, disc heights, segmental and cervical lordotic angles. In addition to these, there were no significant differences between the groups' mean postoperative $1^{\text {st }}, 3^{\text {rd }}$ month and

Table III: Disc Height Measurements of Both Groups

\begin{tabular}{lcccccc}
\hline & Preop & Postop 1 $\mathbf{1}^{\text {st }}$ day & $\begin{array}{c}\text { Early postop } \\
\left(\mathbf{1}^{\text {st }} \mathbf{~} \mathbf{0}\right)\end{array}$ & $\begin{array}{c}\text { Early postop } \\
\left(\mathbf{( 3}^{\text {rd }} \mathbf{~} \mathbf{)}\right)\end{array}$ & $\begin{array}{c}\text { Late postop } \\
(\mathbf{1 2 - 2 4} \mathbf{~ m o})\end{array}$ & $\mathbf{p}$ \\
\hline Group A $(\mathrm{mm})$ & $3.75 \pm 0.32$ & $5.52 \pm 1.15$ & $5.10 \pm 0.90$ & $5.05 \pm 1.05$ & $4.80 \pm 0.95$ & $<0.05$ \\
\hline Group B $(\mathrm{mm})$ & $3.85 \pm 1.0$ & $5.50 \pm 1.15$ & $5.15 \pm 0.90$ & $5.0 \pm 0.85$ & $4.81 \pm 0.78$ & $<0.05$ \\
\hline
\end{tabular}

Table IV: Segmental Lordotic Angle Measurements of Both Groups

\begin{tabular}{|c|c|c|c|c|c|c|}
\hline & Preop & Postop first day & $\begin{array}{l}\text { Early postop } \\
\left(1^{\text {st }} \mathrm{mo}\right)\end{array}$ & $\begin{array}{l}\text { Early postop } \\
\left(3^{\text {rd }} \mathbf{m o}\right)\end{array}$ & $\begin{array}{l}\text { Late postop } \\
\text { (12-24 mo) }\end{array}$ & p \\
\hline Group A* & $0.18 \pm 0.06$ & $4.02 \pm 0.48$ & $2.20 \pm 0.30$ & $1.90 \pm 0.25$ & $1.15 \pm 0.20$ & $<0.05$ \\
\hline Group B* & $0.32 \pm 0.08$ & $4.90 \pm 1.0$ & $3.10 \pm 0.60$ & $2.31 \pm 0.51$ & $1.50 \pm 0.33$ & $<0.05$ \\
\hline
\end{tabular}

*plain (') mean $\pm S D$, mo: Months.

Table V: Cervical Lordotic Angle Measurements of Both Groups

\begin{tabular}{|c|c|c|c|c|c|c|}
\hline & Preop & Postop first day & $\begin{array}{l}\text { Early postop } \\
\left(1^{\text {st }} \mathrm{mo}\right)\end{array}$ & $\begin{array}{l}\text { Early postop } \\
\quad\left(3^{\text {rd }} \mathrm{mo}\right)\end{array}$ & $\begin{array}{c}\text { Late postop } \\
\text { (12-24 mo) }\end{array}$ & p \\
\hline Group A* & $12.10 \pm 1.80$ & $10.60 \pm 1.58$ & $15.60 \pm 2.22$ & $14.10 \pm 2.06$ & $14.04 \pm 1.60$ & $<0.05$ \\
\hline Group B* & $10.65 \pm 1.46$ & $9.40 \pm 1.24$ & $14.32 \pm 2.01$ & $14.01 \pm 1.58$ & $13.52 \pm 1.75$ & $<0.05$ \\
\hline
\end{tabular}

*plain (') mean $\pm S D$, mo: Months. 
$12-24^{\text {th }}$ months' data's for pain VAS scores, Odom's criteria, disc heights, segmental and cervical lordotic angles.

We did not observe misalignment of the cages at the patients of both groups. Additionally, there was no migration or extrusion of the cage at latest follow-up.

\section{DISCUSSION}

Anterior cervical microdiscectomy is routinely used for the treatment of cervical disc herniation, which may cause radiculopathy and/or neurological findings. The ACD procedure was popularized at the end of the 1970's. Firstly, the spine surgeons chose simple ACD procedures. The autografts were added to the ACD procedure to increase the fusion and to provide the alignment of the cervical vertebrae. A few articles were published comparing the simple ACD and auto graft + ACD techniques (2-4). Plating of vertebrae corpus was added to these techniques to prevent the sliding of auto graft, subsiding of disc level and also the alignment of vertebrae $(6,11)$.

The 2000's were the years of spine surgeons because of the marketing of biocompatible products such as PEEK materials, titanium biomedical vehicles, etc. New biocompatible products were marketed to increase the fusion rates; to prevent the alignment and subsidence of operated level besides providing the cervical and segmental angles properly (12). In addition, bladed PEEK cages designed and marketed to prevent the stabilization and extrusion of cages during fusion process after ACD.

The adjacent segment diseases are becoming the main problems of fusion at the postoperative follow-up of cervical discectomy patients. The meta analysis of Anderson et al. (1) showed that there is no statistically significance at the fusion options (PEEK cages, titanium, autografts, plates, and arthroplasty etc.) So, we did not evaluate the adjacent segment diseases in our study.

In this study we compared the classical form of PEEK cages (group A) with the bladed ones (group B). The clinical and radiological outcomes were used for the evaluation of both groups. The VAS scores and Odom's criteria were chosen for clinical evaluation. Postoperative findings of the patients in both groups were excellent in all time periods as compared with the preoperative data $(\mathrm{P}<0.05)$ (Table II). The study of Cabraja et al. (5), which compared the cervical PEEK cages and titanium cages, reported postoperative pain assessments similar to our study.

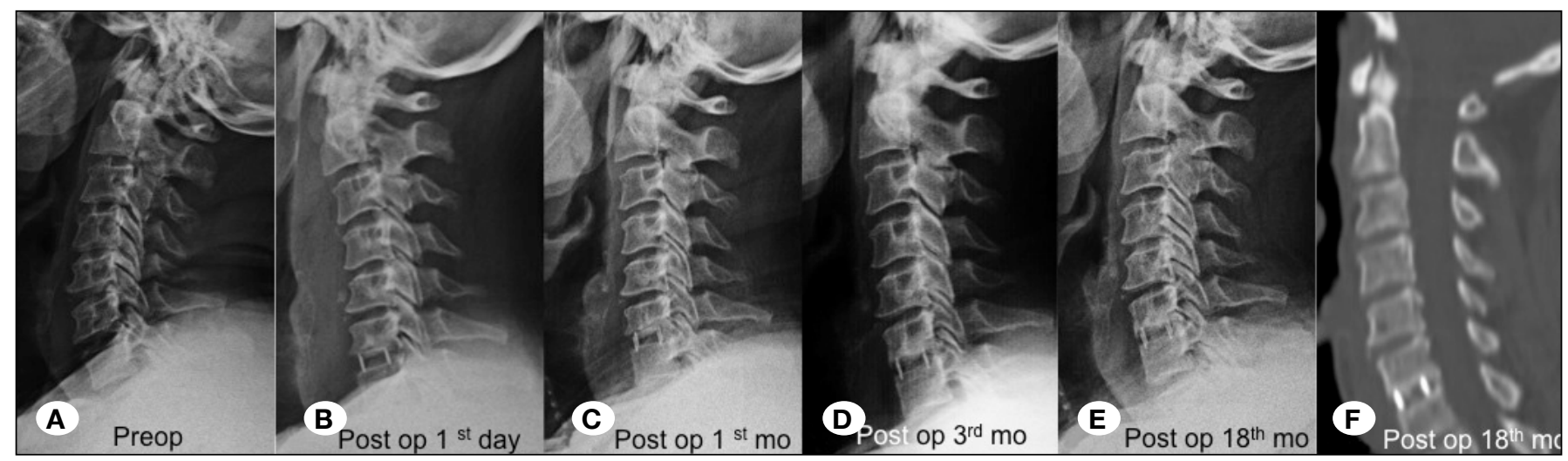

Figure 2A-F: The preoperative, postoperative $1^{\text {st }}$ day, $1^{\text {st }} \mathrm{mo}, 3^{\text {rd }}$ and $12^{\text {th }}-24^{\text {th }}$ mo's lateral plain graphies and late postoperative sagittal CT scans of the patient (group A).

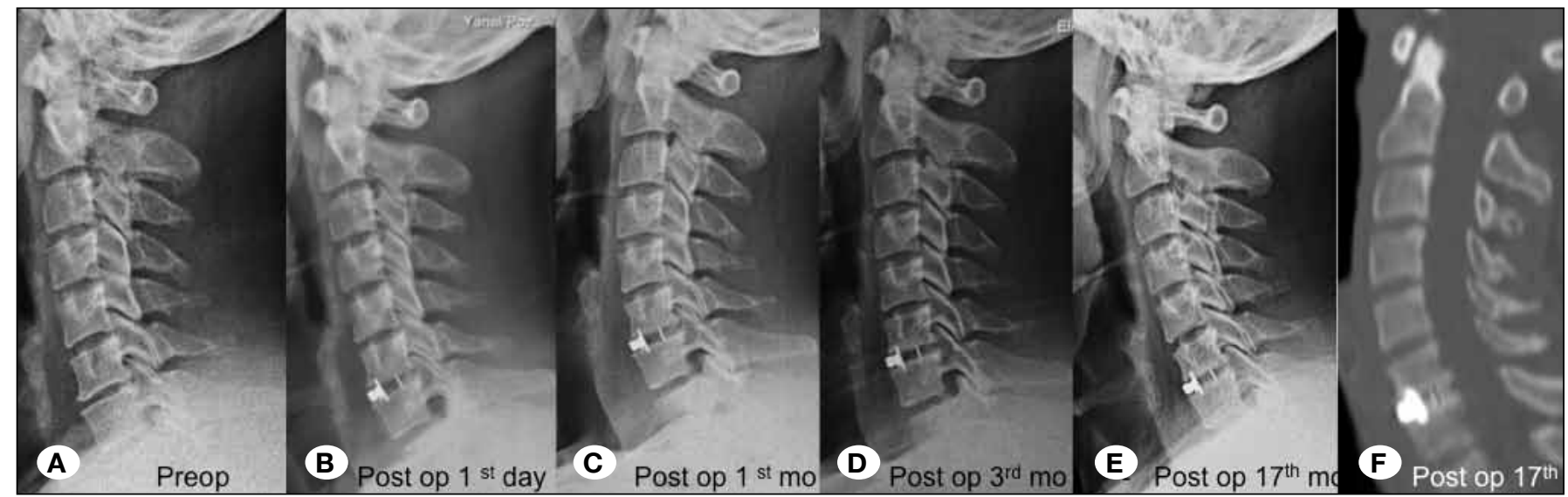

Figure 3A-F: The preoperative, postoperative $1^{\text {st }}$ day, $1^{\text {st }} \mathrm{mo}, 3^{\text {rd }}$ and $12^{\text {th }}-24^{\text {th }}$ mo's lateral plain graphies and late postoperative sagittal CT scans of the patient (group B). 
The comparison of preoperative and postoperative $1^{\text {st }}$ day disc height measurements showed increase at the postoperative $1^{\text {st }}$ day $(p<0.05)$ while at the $1^{\text {st }}, 3^{\text {rd }}$ and $12^{\text {th }}-24^{\text {th }}$ mo's follow-up there was a minimal decrease at these levels. However, the comparison of preoperative and postoperative $12^{\text {th }}-24^{\text {th }}$ mo disc height measurements also showed significant difference $(p<0.05)$ (Table III). The literature evaluations revealed that subsidence is the main problem of all ACD and fusion techniques. These results were similar with our previous studies $(7,13)$. Beside these, the study of Yang et al. (18) declared similar postoperative results with our study.

The segmental lordotic angles of the operated levels increased at the postoperative $1^{\text {st }}$ day as compared with the preoperative data in both groups. Although the $1^{\text {st }}, 3^{\text {rd }}$ and $12-24^{\text {th }}$ mo's measurements decreased with the comparison of postoperative $1^{\text {st }}$ day measurements $(p<0.05)$, they were still showing an increase with the preoperative segmental angle measurements in both groups $(p<0.05)$. The statistical evaluations were not significant for inter-group comparisons (Table IV). Kulkarni et al. (10) reported an article similar with our group A. In their study, the segmental angle increased at the early postoperative period and decreased at the late follow-up measurements. But, the decrease at the late follow-up was smaller than the preoperative measurements. We think that the degenerative disc disease itself cause this insignificant decrease at the late follow-up.

The measurements of cervical lordotic angles of both groups were not similar with the segmental angle measurements. The cervical lordotic angles of the operated levels decreased at the postoperative $1^{\text {st }}$ day as compared with the preoperative data in both groups but these decreases were not significant. We think that the muscle spasm due to the manipulation during the operation may be the cause of cervical angle decrease at the postoperative $1^{\text {st }}$ day, in both groups. However, the cervical angle measurements increased at the $1^{\text {st }}, 3^{\text {rd }}$ and $12-24^{\text {th }}$ mo's measurements, respectively in both groups $(p<0.05)$. The inter-group statistical evaluations were not significant in all time measurements (Table V). These results were not similar to our previous studies (7). In our previous study, we had detected decrease at the early followup period compared with the preoperative measurements. The late follow-up measurements were still smaller than the preoperative measurements despite the increased values. In addition, Song et al. (16) revealed an increase in both the early and late follow-up period measurements in their three levels PEEK cage study. We think that the difference of cage styles and levels may cause these results.

Discussion of fusion is a popular topic at the literature $(9,16)$. The fusion of the operated levels was evaluated at the $3^{\text {rd }}$ and $12^{\text {th }}-24^{\text {th }}$ time period after operation in our study. The comparison of fusion rates at the operated levels of all patients in the $3^{\text {rd }}$ and $12^{\text {th }}-24^{\text {th }}$ months after surgery showed no significance between the groups. While the $3^{\text {rd }}$ month follow-up of both groups showed $55 \%$ and $60 \%$ fusion rates, respectively, the $12^{\text {th }}-24^{\text {th }}$ month follow-up showed $100 \%$ good and excellent fusion. Kulkarni et al. (10) reported 100 $\%$ fusion rates at the late follow-up period in their single level study while Song et al. (16) reported pseudoarthrosis and cage related problems in their multilevel study.

\section{- CONCLUSION}

Both cervical PEEK cage and bladed PEEK cage groups showed similar satisfactory clinical and radiological outcomes that were maintained over 12-24 mo's time period. Both cervical PEEK cage and bladed PEEK cage groups appear to be viable options for the treatment of single-level cervical radiculopathy.

\section{REFERENCES}

1. Anderson PA, Sasso RC, Hipp J: Kinematics of the cervical adjacent segments after disc arthroplasty compared with anterior discectomy and fusion: A systematic review and meta-analysis. Spine 37: S85-95, 2012

2. Bertalanffy $H$, Eggert HR: Clinical long-term results of anterior discectomy without fusion for treatment of cervical radiculopathy and myelopathy. A follow up of 164 cases. Acta Neurochir 90: 127-135, 1988

3. Brigham CD, Tsahakis PJ: Anterior cervical foraminotomy and fusion: Surgical techniques and results. Spine 20: 766-770, 1995

4. Buchowski JM, Liu G, Bunmaprasert T, Rose PS, Riew DK: Anterior cervical fusion assessment: Surgical exploration versus radiographic evaluation. Spine 33:1185-1191, 2008

5. Cabraja M, Ozdemir S, Koeppen D, Kroppenstedt S: Anterior cervical discectomy and fusion: Comparison of titanium and polyetheretherketone cages. BMC Musculoskelet Disord 13:172, 2012

6. Coric D, Kim PK, Clemente JD: Prospective randomized study of cervical arthroplasty and anterior cervical discectomy and fusion with long-term follow up: Results in 74 patients from a single site. J Neurosurg Spine 18:36-42, 2013

7. Cosar M, Ozer AF, Iplikcioglu AC: The results of beta-tricalcium phosphate coated hydroxyapatite (beta-TCP/HA) grafts for interbody fusion after anterior cervical discectomy. J Spinal Disord Tech 21:436-441, 2008

8. Faldini C, Chehrassan M, Miscione MT: Single-level anterior cervical discectomy and interbody fusion using PEEK anatomical cervical cage and allograft bone. J Orthop Traumatol, 12: 201-205, 2011

9. Goldstein C, Drew B: When is a spine fused? Injury 42: 306 313, 2011

10. Kulkarni AG, Hee HT, Wong HK: Solis cage (PEEK) for anterior cervical fusion: Preliminary radiological results with emphasis on fusion and subsidence. Spine J 7:205-209, 2007

11. Martins AN: Anterior cervical discectomy with and without interbody graft. J Neurosurg 44: 290-295, 1976

12. Mobbs RJ, Chau AM, Durmush D: Biphasic calcium phosphate contained within a polyetheretherketone cage with and without plating for anterior cervical discectomy and fusion. Orthop Surg 4: 156-165, 2012

13. Oktenoglu T, Cosar M, Ozer AF: Anterior cervical microdiscectomy with or without fusion. J Spinal Disord Tech 20: $361-368,2007$ 
14. Pechlivanis, I, Thuring T, Brenke C: Non fusion rates in anterior cervical discectomy and implantation of empty polyetheretherketone cages. Spine 36:15-20, 2011

15. Rosenorn J, Hansen EB, Rosenorn MA: Anterior cervical discectomy with and without fusion. A prospective study. J Neurosurg 59: 252-255, 1983

16. Song KJ, Kim GH, Choi BY: Efficacy of PEEK cages and plate augmentation in three-level anterior cervical fusion of elderly patients. Clin Orth Surg 3: 9-15, 2011
17. Tureyen K: Disc height loss after anterior cervical microdiscectomy with titanium intervertebral cage fusion. Acta Neurochir 145: 565-570, 2003

18. Yang JJ, Yu CH, Chang BS, Yeom JS, Lee JH, Lee CK: Subsidence and nonunion after anterior cervical interbody fusion using a stand-alone polyetheretherketone (PEEK) cage. Clin Orthop Surg 3:16-23, 2011 